\title{
Nipah Virus Mystery: Insight into Transmission and Mechanism of Disease Progression
}

\author{
Dania Hassan $^{1}$ (D), Roshni Ravindran ${ }^{1}$ and Ashfaque Hossain ${ }^{1,2 *}$ (D) \\ ${ }^{1}$ Department of Medical Microbiology and Immunology, RAK Medical and Health Sciences University, \\ Ras Al Khaimah, UAE. \\ ${ }^{2}$ Central Research Laboratory, RAK Medical and Health Sciences University, Ras AI Khaimah, UAE.
}

\begin{abstract}
Nipah virus (NiV) belongs to the biosafety level four (BSL-4) group of human pathogens of zoonotic origin. It is an emerging pathogen capable of causing a variety of clinical presentations, including encephalitis and severe acute respiratory illness, which can be fatal. Interestingly, it can also cause asymptomatic infections, which can relapse after a long period of time ranging from months to years following initial infection. Zoonotic transmission involves bats or pigs. In addition, transmission via contaminated food and occasional human to human direct transmission may also occur. It can have diverse epidemiological features and can have a very high case fatality ratio. Although a variety of immunological and molecular assays have been developed and epidemiological monitoring procedures for this disease have been introduced, there are no drugs available for this virus. Vaccines are at different stages of development. In this mini-review, we present the latest information on the Nipah virus; primarily focusing on emergence, transmission, pathogenic mechanisms and possible prophylactic and treatment options.
\end{abstract}

Keywords: Nipah, virus, zoonosis, outbreak

(C) The Author(s) 2022. Open Access. This article is distributed under the terms of the Creative Commons Attribution 4.0 International License which permits unrestricted use, sharing, distribution, and reproduction in any medium, provided you give appropriate credit to the original author(s) and the source, provide a link to the Creative Commons license, and indicate if changes were made. 


\section{INTRODUCTION}

Nipah virus (NiV) is a zoonotic pathogen belonging to the family Paramyxoviridae and genus Henipavirus. NiV is transmitted by infected Pteropus bats and contaminated fruits. ${ }^{1}$ Human to human transmission renders the infection very contagious. ${ }^{2} \mathrm{NiV}$ can cause a variety of illnesses ranging from asymptomatic infection to fatal neurological and respiratory manifestations, with a mortality rate of more than $75 \%$ and sometimes reaching to $100 \%$. The capacity of transinfection (unproductively infecting immune cells and using it as a carrier to transmit the virus to different body sites) by the virus is considered as it's a unique characteristic feature that contributes to the high pathogenicity of this virus. ${ }^{3}$ It is a very deadly and highly transmissible, biosafety level 4 (BSL-4) virus, and there are neither therapeutic nor prophylactic treatments yet, making it a serious public health concern. ${ }^{4}$

\section{About Nipah virus (NiV)}

$\mathrm{NiV}$ is an enveloped, negative-sense, zoonotic RNA virus with a single stranded, unsegmented genome of approximately 18.2 $\mathrm{kb}$ in size. ${ }^{5}$ It was first isolated from the village 'Sungai Nipah', in Malaysia; hence it has been given the name "Nipah". ${ }^{6}$ It is a member of the Paramyxoviridae family and its natural host is fruit bat (Pteropus spp), also known as the flying fox. In addition, it can naturally infect several other animals, including cats, dogs, pigs, and horses. ${ }^{7}$ A total of nine proteins are encoded from the genome of NiV; six structural and 3 non-structural proteins. The 3 non-structural proteins are $C, V$ and $\mathrm{W}$, which play critical roles in the pathogenesis of NiV, regulating the early host pro-inflammatory response, and development of the respiratory manifestations. ${ }^{4,8}$ The six major structural proteins include matrix protein $(\mathrm{M})$, nucleocapsid (N), fusion protein $(F)$, phosphoprotein $(P)$, glycoprotein $(G)$, and large protein (L). The oro-nasal route is used by NiV to get into the host. Glycoprotein G of NiV serves as the ligand that binds to the host cell surface receptors, while Ephrin B2 and Ephrin B3 serve as the receptors. ${ }^{9}$ The ligand and receptor interaction leads to the fusion of viral membrane with cellular membrane resulting in disassembling of viral capsid and the release of viral genome into the cell. ${ }^{10}$ Four NiV proteins $(\mathrm{P}, \mathrm{V}, \mathrm{W}$, and $\mathrm{C}$, all encoded by the $P$ gene) play important roles in evading the innate immune response of the host and establishing successful infection. ${ }^{11}$ The interferon based antiviral response is initiated in the host following infection and viral protein $\checkmark$ plays the key role in the evasion of interferon (IFN- $\alpha$ and IFN- $\gamma$ ) response. ${ }^{12}$ The $V$ protein inhibits tyrosine phosphorylation of STAT proteins, thus preventing translocation to these proteins to the nucleus and subsequent induction of IFN- $\alpha$ and IFN- $\gamma$. Systemic NiV infection is characterized by the presence of viral antigens in different body sites such as respiratory tract, neurons, lymphoid tissues, and the endothelial cells lining blood vessels. ${ }^{4}$ The site of initial replication is still unknown, as the human tissue samples investigated were mostly collected from those with the terminal stages of the disease. However, as analysis of lymphoid and respiratory tissue samples was done, and revealed the presence of high concentrations of viral antigens, these tissues represent the probable sites of initial replication. ${ }^{13}$ Due to its high virulence and transmissibility of NiV, it is one of the top pathogens most likely to cause major epidemics in the near future. ${ }^{14}$

\section{Epidemiology}

The first cases of NiV infection appeared in late September 1998, at a pig farm, in the village Sungai Nipah, district Perak, Malaysia. The disease presented as a febrile illness with encephalitis in humans and as respiratory and neurological symptoms in pigs.,15 During this first recognized outbreak in Malaysia, Singapore, a neighbouring country of Malaysia was also affected through import of infected pigs from Malaysia and this outbreak was known as the Malaysia-Singapore outbreak, which resulted in 276 infections and 106 deaths. ${ }^{16}$ Sporadically, small scale outbreaks continued to occur in that region which, however, ceased within one year of the initial report. From 1999, outbreaks of NiV infections were emerging in Bangladesh and India. ${ }^{17}$ Initially, the cases were thought to be caused by Japanese encephalitis virus (JEV), as some serum samples collected from NiV cases tested positive for JEV specific IgM (due to a previous outbreak of Japanese encephalitis in Malaysia). However, several features of NiV outbreak ruled out JEV as the possible pathogen. Unlike with JEV epidemic, most patients in NiV epidemic were adult males, not children. In addition, most patients in NiV 
were in direct physical contact with pigs, unlike in the case of JEV, which is a mosquito-borne disease. Furthermore, there were reports of ill pigs developing a severe barking cough and eventually dying from the disease, which was also not a feature of JE. Virologists from the University of Malaya (Kuala Lumpur, Malaysia) isolated the new virus from cerebral spinal fluid (CSF) of infected patients in 1999 and was categorized in the family Paramyxoviridae. ${ }^{6,16}$

\section{Outbreaks in Malaysia and Bangladesh}

Two different modes of transmission of NiV were observed when the transmission in Malaysia-Singapore outbreak was compared with the transmission in Bangladesh-India outbreak. In Malaysia-Singapore outbreak, transmission occurred from bats to pigs to humans. ${ }^{1}$ In contrast, analysis have shown seasonal outbreaks in Bangladesh, where transmission of NiV to humans takes place when people consume contaminated raw date palm sap with bat's secretions, during the winter season (harvest season for date palm sap). ${ }^{17,18}$ Subsequently, the cycle of person-toperson transmission is initiated as the virus can be transmitted via droplet infection. ${ }^{13,19}$ Nipah Virus isolates in Bangladesh (NiV-Bangladesh) are reported to be capable of efficient person to person transmission, occurring in all outbreaks in this geographic region. ${ }^{2}$ The saliva of patients is commonly tested positive for NiV and contributes to droplet transmission. The difference between the mode of transmission in both countries is

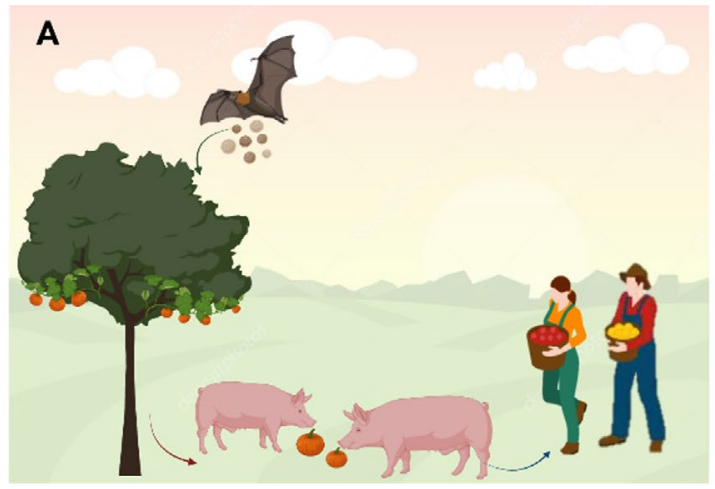

shown in Fig. 1. Following the first outbreak in 2011, several countries of East Asia and South East Asia (Malaysia, India, Bangladesh, Indonesia, Vietnam, Thailand, Papua New Guinea, East Timor) witnessed sporadic outbreaks of NiV almost every year. ${ }^{13}$ In 2021, two NiV cases were reported in Bangladesh in September 2021. ${ }^{20}$ which is less than the incidence of the year prior ( 6 cases were reported).

\section{Outbreaks in Kerala, India}

The Indian state of Kerala has become a hot spot of NiV infection with 3 outbreaks since 2018. After the first outbreak in 2018, the second outbreak was in 2019, and the most recent outbreak occurred in September 2021. ${ }^{21}$ During the first outbreak in 2018 in the Kozhikode district, Kerala, the first patient had a febrile illness and was diagnosed to have acute respiratory distress syndrome (ARDS); NiV was detected, and the patient did not survive. This incidence was followed by a series of 18 cases that tested positive for the virus; ${ }^{16}$ of them did not survive. Strict infection control methods were followed, and fortunately, this outbreak was controlled without an increase in the number of cases. ${ }^{22}$ In the 2019 outbreak, only one case was reported in the Ernakulam district of Kerala, and there was no death. During the 2018 outbreak, bats were screened with $19 \%$ appearing positive for NiV and $33 \%$ of the screened bats were positive during the outbreak in $2019 .{ }^{23}$ The 2021 outbreak, which started in September, again occurred in the district

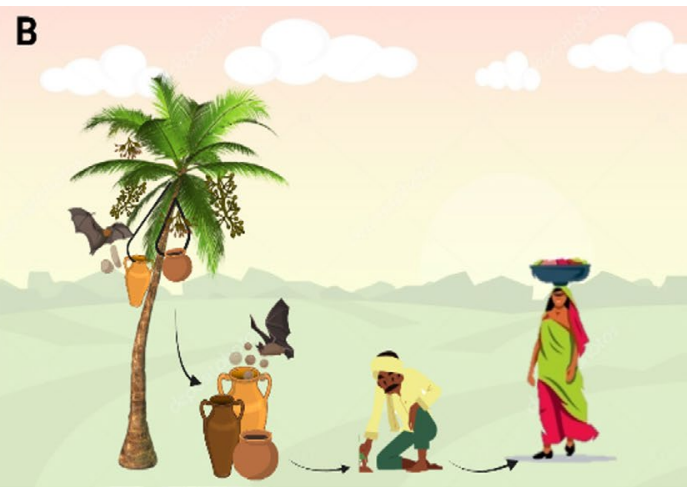

Fig. 1. Difference in transmission of Nipah virus between the Malaysian outbreak and Bangladeshi outbreak. (A) Shows the mode of transmission in Malaysia; bats roosting in fruit trees contaminate fruits, which are in turn are consumed by pigs, then pig to human transmission occurs. (B) Shows mode of transmission of NiV in Bangladesh, during the winter months, the season of harvesting date palm sap, the fruit bats contaminate the date palm sap stream and sap collection containers with saliva or urine. Subsequently, consumption of contaminated raw date palm sap leads to human infection, thus person-person transmission is initiated. 
Kozhikode of Kerala. This resulted in the death of a boy who reportedly ate a bat bitten fruit. In addition to other symptoms, he had encephalitis and myocarditis. ${ }^{21}$ Following transmission of the bats to the livestock, amplification of the virus occurs in the infected host, thus creating an ideal situation for a person-to-person aerosol borne transmission. The NiV circulating Kerala is reported to be genetically same as NiV-Bangladesh (NiV-B). Genome comparison revealed that NiV-B diverged significantly from NiV-M (Nipah virus from Malaysia, the original NiV which first appeared in 1998). ${ }^{24}$ It is interesting to note that although NiV-Bangladesh (NiV-B) is causing infection almost every year in Bangladesh and infrequently in India, there has been no report of re-emergence of NiV-M). ${ }^{24,25}$

The most common route of transmission of $\mathrm{NiV}$ is through the oro-nasopharyngeal route. Initial replication of the virus is thought to happen in the respiratory airways, then systemic dissemination of NiV takes place targeting the endothelial cells in multiple organs. ${ }^{7}$ The microvascular endothelial cells in the central nervous system are primarily infected by the virus and this represents the clinical manifestation of multifocal encephalitis. The pathologic effect of NiV was most pronounced on medium-size and small blood vessels. This virus-associated microangiopathy and subsequent ischemic microinfarction was detected by MRI. ${ }^{15}$ Moreover, autopsy samples of NiV victims showed multiorgan involvement; pathological lesions with disseminated microinfarction due to vasculitis induced thrombosis and direct tissue involvement was noted in the brain, respiratory tract, heart, and kidneys. ${ }^{26}$ Nipah Virus suppresses the host antiviral response, by targeting multiple host proteins. Once the virus overcomes the innate immunity barrier, systemic dissemination of the virus occurs. Therefore, viral antigen can be detected in various organs across the body. ${ }^{17}$

The viral proteins engage in overcoming the innate immune response. ${ }^{8}$ Experimentally, it has been found that NiV was unable of successfully infecting human lymphocytes or monocytes; instead, it efficiently bound to lymphocytes and utilized them to transfer the infection to different parts of the body. This unique mode of potent

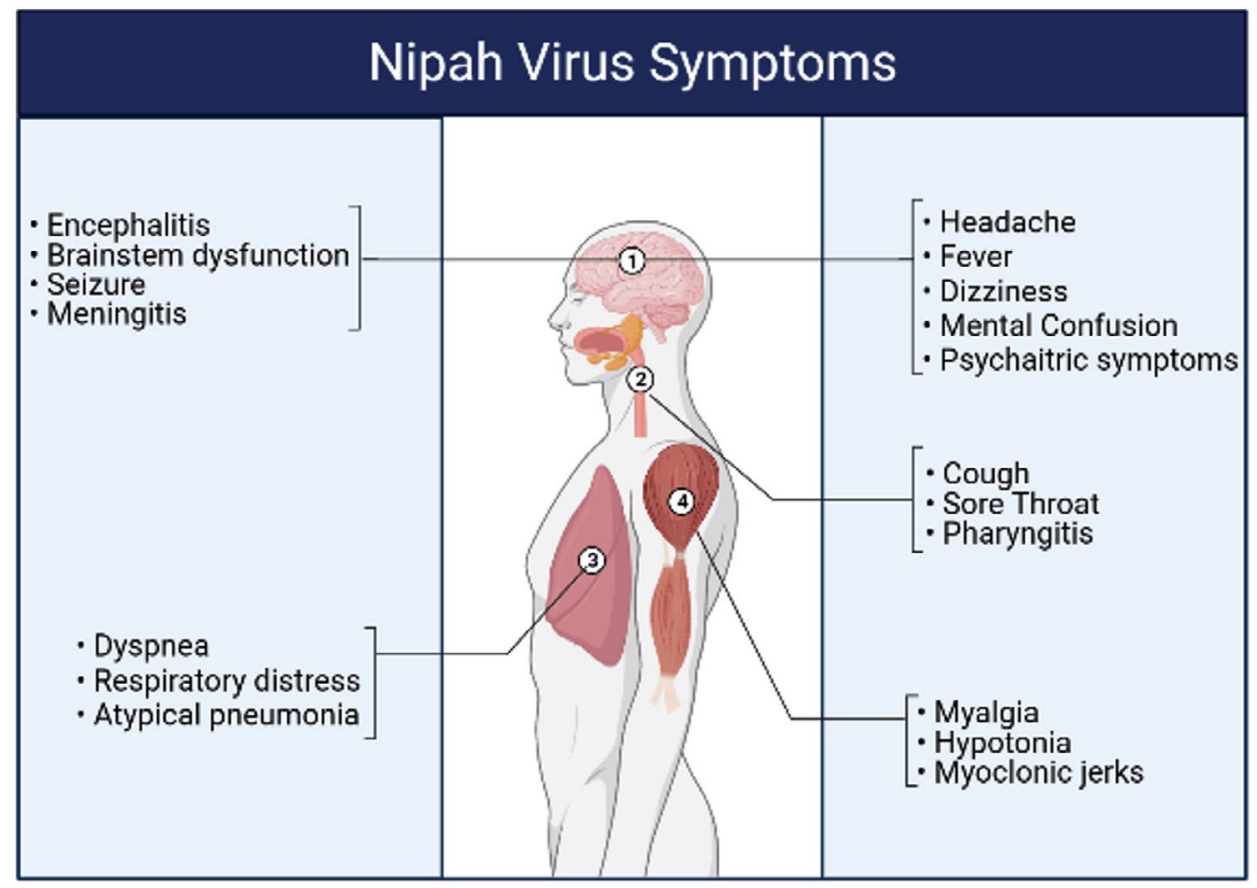

Fig. 2. A variety of clinical features that can develop in patient with NiV are shown in this figure. A small percentage of infected people remain asymptomatic. Prodromal symptoms like fever, headache, and myalgia appear in the early stages of the diseases. Encephalitis and respiratory distress are the severe forms of the disease. Encephalitis can relapse after long period time (months to years) following the recovery from the initial infection. 
systemic dissemination of the virus, is termed as transinfection. In NiV infection model in the hamster, leukocytes were capable of capturing and carrying NiV without themselves being successfully infected. Such NiV-loaded mononuclear leukocytes transfer lethal NiV infection into naïve animals, demonstrating efficient virus transinfection in vivo. Treatment of NiV-bound lymphocytes with protease and neutralizing antibodies to the virus rendered such cells incapable of transferring infection, demonstrating that virus attached to the cells but there was no internalization. ${ }^{3} \mathrm{NiV}$ is thus capable of hijacking leukocytes and using them as their carrier to spread the virus to various body systems and infect the host cells. Transinfection is considered to contribute to the rapid and high pathogenicity of NiV. ${ }^{3,28}$

\section{Clinical features}

The incubation period of NiV following infection is of variable duration depending upon the host, ranging from 4-21 days. Few infected people remain asymptomatic. Majority of the cases manifest primarily with acute encephalitis and respiratory illness which are markedly life-threatening. ${ }^{29}$ The illness initially presents as 3-14 days of fever, headache, fatigue, and muscle ache. In addition, it often includes signs of respiratory illness, such as cough, sore throat, and difficulty breathing. ${ }^{30}$ Within a week, a phase of encephalitis begins, where symptoms can include dizziness, vomiting, altered consciousness, mental confusion, hypotonia and prominent signs of brainstem dysfunction, including mycolic jerks, vasomotor changes, and abnormal doll's eye and pupillary reflexes. In severe cases, seizures are common and can rapidly progress to coma. Fig. 2, summarizes the symptoms experienced by NiV-infected patients. Neurologic involvement can be more diverse, including aseptic meningitis and diffuse encephalitis. Two unique clinical features have been reported in a few cases; these are late-onset encephalitis and relapse. ${ }^{31}$ The later refers to encephalitis that can relapse months or years following recovery from initial infection. While late-onset encephalitis refers to delayed development of encephalitis in a person who did not suffer from it during the initial infection. Various psychiatric features, including attention deficits, depression and personality changes, were reported also reported, which often are apparent after infection is resolved. ${ }^{4}$

When comparing the Malaysian and Bangladeshi outbreaks, few differences in clinical features were described. Cases in Bangladesh and India had higher rates of respiratory involvement as well as higher mortality rates, as opposed to cases in Malaysia where respiratory involvement was immensely lower. However, Neurological manifestations and neuropsychiatric changes were more prominent in the Malaysian outbreak cases than in Bangladeshi ones. ${ }^{32}$

\section{Diagnosis}

Symptoms of NiV infection are often nonspecific and are similar to other viral infections, hence early diagnosis is crucial for initiation of appropriate patient care, and for implementation of appropriate epidemiological measures for the confinement of the outbreak. NiV should be suspected in people with constitutional symptoms who have been in areas where Nipah is more common. ${ }^{33}$ It is also necessary to rule out other infectious diseases that are common in those regions, like malaria, West Nile virus infection, dengue infection, and Japanese encephalitis. Thorough clinical history along with laboratory tests should be performed to diagnose the infection. ${ }^{34}$ Procedures for laboratory diagnosis include ELISA, serology, polymerase chain reaction (PCR), immunohistochemistry, histopathology, and virus isolation. ${ }^{4}$

PCR

The most commonly used initial test for rapid detection of NiV is RT-PCR (reverse transcriptase-polymerase chain reaction). It is a highly sensitive and highly specific technique for rapid detection of the virus in the early stages of the infection. ${ }^{35}$ Specimens can be gathered from a symptomatic patient's blood, CSF, urine, tissue samples, and nasopharyngeal swabs. ${ }^{4}$

\section{ELISA}

In the later stage of infection, antibody detection can be carried out using ELISA. This serological test is used to detect IgM and IgG antibodies. IgM antibodies are detectable during the first five days of symptomatic illness in more than $50 \%$ of patients. ${ }^{6,36}$ Both IgM and IgG were universally present in the sera of patients who survived 2 weeks post-infection. Although IgG positivity persists for several months, IgM levels start decreasing by 2-3 months of onset of 
symptoms and eventually become negative in all survivors. Since IgG persists for long period of time after convalescence, its detection by ELISA is used for seroprevalence studies and surveillance. ${ }^{37}$

\section{Virus Isolation}

Virus isolation can be carried out using Vero E6 cells, human lung fibroblast cells (MRC5) and human neuronal cells (SK-N-MC). ${ }^{38}$ The clinical samples can be taken from respiratory secretions, urine, CSF, or any other tissue specimen for virus isolation. The virus has the ability to induce syncytia formation with nuclei arranged around the periphery. This arrangement differs from most syncytia seen in cell cultures induced by Hendra virus, a closely related virus. Definitive identification of the virus from cell culture can be done by PCR or immunohistopathology. In view of the fact that NiV is a BSL-4 pathogen, an utmost care is required when processing the clinical samples. ${ }^{30}$

\section{Immunohistochemistry}

Immunohistochemistry is carried out on formalin-fixed-tissue to preserve the cellular morphology and proteins. For proper diagnosis, it is important to analyse various tissue samples, not solely the lung or brain, as the virus can replicate in a vast range of tissues such as lung, brain, spleen, kidney and lymph nodes, and uterus, as its primary site of infection. ${ }^{37,40}$ Serum neutralisation test (SNT) in cell culture is considered and accepted as the reference standard test, and just like the virus isolation, it requires a BSL-4 facility. ${ }^{4}$

\section{Prevention}

Although the virus can be transmitted easily from person to person, it is possible to control its spread by adopting combination of interventions. First of all, practicing proper handwashing regularly with soap and water should be encouraged. Moreover, it's crucial to raise awareness among populations at higher risk about the signs, symptoms, and complications of Niv. Furthermore, efforts should be made to make people in high-risk areas aware of how consumption of raw date sap can cause infection that spreads readily from person to person. ${ }^{41}$ According to the $\mathrm{WHO}$ guideline for containing NiV outbreaks, thorough cleaning and disinfection of pig farms should be done routinely, movement of animals out of an infected farm should be banned, Animal premises should be isolated immediately when an outbreak is suspected.1 Efforts towards prevention of transmission of NiV need to focus on the following; (a) boiling of freshly collected date sap (b) thorough washing and peeling of fruits before consumption (c) discarding fruits with signs of bat bite (d) use protective date palm coverings (such as bamboo sap skirts) to decrease access of bats to date palms saps (e) Gloves and other protective clothing should be worn while handling sick animals or their tissues. Suspected infected people and their contacts should be isolated until they recover or prove they are not infected. ${ }^{13}$ (Health-care workers caring for patients with suspected or confirmed infection or handling specimens from them should implement standard infection control precautions at all times. Surveillance programs of animals and people should be implemented in areas where NiV is known to exist. ${ }^{24}$

\section{Treatment}

According to WHO Research and Development Blueprint, NiV infection is a priority disease. ${ }^{1}$ As there are no specific drugs or vaccines, hospitalization for supportive care and close observation is generally required to optimize survival. ${ }^{1,43}$ Treatment can only relieve the symptoms and treat severe respiratory and neurologic complications but cannot eliminate the disease entirely. Supportive care might consist of anticonvulsants, treatment of secondary infections, mechanical ventilation, and rehabilitation. Ribavirin and purine nucleoside analogue have shown effectiveness against the Nipah virus; however, more studies are required to confirm these findings that have been largely based on in vitro data and few human studies. ${ }^{44}$ Remdesivir, a potent antiviral nucleotide analogue prodrug, is reported to be efficacious against the lethal challenge of NiV in the African green monkey model. Although, mild respiratory symptoms were observed, the drug could protect the experimental monkeys against NiV challenge, whereas all the control animals with no drug succumbed to infection. ${ }^{45}$ Favipiravir, a purine analogue antiviral drug has been found to inhibit replication of Nipah Virus in in vitro cell culture and the drug also fully protected hamsters in lethal challenge experiments. ${ }^{46}$ During the 2018 Nipah outbreak in Kerala, M102.4 was imported for treating patients though it was not used as the outbreak ended. 
M102.4, a monoclonal antibody which recognizes the $\mathrm{G}$ envelope protein of NiV and appears to block the receptor-binding site on the protein preventing adhesion of the virus to the Ephrin B2 receptor protein and thereby inhibiting viral entry into the host cell. ${ }^{47}$

\section{Vaccine}

Three characteristics make Nipah virus (NiV) a pathogen of pandemic potential, (a) high pathogenicity (b) capacity to infect humans either directly from natural reservoirs or following amplification in an intermediary animal host and (c) capacity to initiate human to human transmission. ${ }^{2,28}$ The WHO declared NiV to be a priority pathogen likely to cause outbreaks, requiring urgent intervention and critical exploration. The development of highly effective and durable vaccines against this virus remains a key priority in order to prevent forthcoming outbreaks. Global efforts gathered to develop an efficient vaccine and as a result, a Hendra virusNipah virus recombinant vaccine, HeV-sG-NiV, has been developed. ${ }^{48} \mathrm{NiV}$ and HeV have strong resemblance as they are both enveloped, singlestranded negative sense RNA virus and both are bat-borne zoonotic pathogens; implying that a single recombinant subunit vaccine against both Nipah and Hendra virus may be possible. A portion of the $\mathrm{G}$ glycoprotein of Hendra virus (HeV-sG) has been used to develop a subunit vaccine against both viruses. This recombinant vaccine has been found to protect against both viruses in several animal models including pigs. ${ }^{49,50}$ Pigs are used as a model for the development of a vaccine against NiV for pigs. ${ }^{49}$ These preclinical findings support the initiative to vaccinate the people at risk. This Hendra-sG vaccine has been approved in Australia for use in horses to vaccinate against the Hendra virus. $^{48,51}$

\section{CONCLUSION}

NiV causes lethal zoonotic disease affecting primarily the respiratory and nervous system. It emerged 23 years ago in Malaysia and it continues to be a cause of severe morbidity and mortality in Bangladesh and India (mainly in the state of Kerala), two neighbouring countries located in the South-East Asia region. The virus causes a neuro-respiratory disease with clinical features ranging from asymptomatic infection to severe encephalitis and respiratory distress with high mortality. Currently, there are no effective therapeutic agents leaving prevention of infection and supportive care as the mainstays of management. Fortunately, several vaccines are at different stages of preparation and are already showing promising results on animals. The lack of easily available and affordable diagnostic tests and equipped facilities to handle viral samples make diagnosis challenging. Threats of probable outbreaks are rising, as the Pteropus bats, the reservoir of NiV has been found in many countries. NiV from the natural reservoir (bats) can directly infect humans and indirectly via livestock following the amplification of the virus. Moreover, NiV has recognized capacity for human to human, and nosocomial transmission. Also, every time the virus infects a human being, it gets exposed to the human environment, which elects for more adaptation and transmissibility in humans. Considering these facts, the epidemiologists are of the opinion that NiV has the potential to cause a pandemic in future.

\section{ACKNOWLEDGMENTS}

The authors would like to thank Dr. G. M. Rao, President, RAK Medical and Health Sciences University, United Arab Emirates for his encouragement and support. Also thanks to Professor Manjurul Karim for doing the iThenticate analysis of the manuscript.

\section{CONFLICT OF INTEREST}

The authors declare that there is no conflict of interest.

\section{AUTHORS' CONTRIBUTION}

$\mathrm{DH}$ and RR collected information. $\mathrm{DH}$ drafted the manuscript. $\mathrm{DH}$ and $\mathrm{AH}$ edited the manuscript. AH approved the final manuscript for publication.

\section{FUNDING} None.

\section{DATA AVAILABILITY}

All datasets generated or analyzed during this study are included in the manuscript. 


\section{ETHICS STATEMENT}

Not applicable.

\section{REFERENCES}

1. WHO, Nipah virus infection. World Health Organization.2018. www.who.int/csr/disease/nipah/ en/

2. Gurley ES, Montgomery JM, Hossain MJ, et al. Persontoperson transmission of Nipah virus in a Bangladeshi community. Emerg Infect Dis. 2007;13(7):1031-1037. doi: 10.3201/eid1307.061128

3. Mathieu C, Pohl C, Szecsi J, et al. Nipah virus uses leukocytes for efficient dissemination within a host. J Virol. 2011;85(15):7863-7871. doi: 10.1128/ JVI.00549- 11

4. Ang BSP, Lim TCC, Wang L. Nipah virus infection. J Clin Microbiol. 2018;56(6):1875-1917.

5. Wang L-F, Harcourt BH, Yu M, et al. Molecular biology of Hendra and Nipah viruses. Microbes Infect. 2001;3(4):279-287. doi: 10.1016/S12864579(01)01381-8

6. Chua KB, Bellini WJ, Rota PA, et al. Nipah virus: a recently emergent deadly paramyxovirus. Science. 2000;288(5470):1432-1435. doi: 10.1126/ science.288.5470.1432

7. Sing RK, Dhama K, Chakrabarty S, et al. Nipah virus: epidemiology, pathology, immunobiology and advances in diagnosis, vaccine designing and control strategies a comprehensive review. Vet Quarterly. 2019;39(1):2655. doi: 10.1080/01652176.2019.1580827

8. Satterfield BA, Cross RW, Fenton KA, et al. The immunomodulating $V$ and $W$ proteins of Nipah virus determine disease course. Nat Commun. 2015;6:7483. doi: $10.1038 /$ ncomms 8483

9. Negrete OA, Levroney EL, Aguilar HC, et al. EphrinB2 is the entry receptor for Nipah virus, an emergent deadly paramyxovirus. Nature. 2005;21(7049):401-405. doi: 10.1038 /nature03838

10. Lee B, Rota PA. Henipavirus: ecology, molecular virology, and pathogenesis. 2012. Springer, Heidelberg, Germany. doi: 10.1007/978-3-642-29819-6

11. Martinez-Gil L, Vera-Velasco NM, Mingarro I. Exploring the human-Nipah virus protein-protein interactome. J Virol. 2017 91(23):e01461-17. doi: 10.1128/ JVI.01461-17

12. Keiffer TR, Ciancanelli MJ, Edwards MR, Basler CF.Interactions of the Nipah Virus $P, V$, and $W$ proteins across the STAT family of transcription factors. mSphere. 2020;5(6):e00449-20. doi: 10.1128/ mSphere.00449-20

13. Aditi, Shariff M. Nipah virus infection: A review. Epidemiol Infect. 2019;147:e95. doi: 10.1017/ S0950268819000086

14. Sun B, Jia L, Liang B, Chen Q, Liu D. Phylogeography, transmission, and viral proteins of Nipah virus. Virol Sin. 2018;33(5):385-393. doi: 10.1007/s12250-0180050-1

15. Goh GX, Tan K, Ang BSP, Wang LF, Lim CCT. Neuroimaging in zoonotic outbreaks affecting the central nervous system: Are we fighting the last war? Am J Neuroradiol. 2020;41(10):1760-1067. doi: 10.3174/ajnr.A6727
16. Chua KB. The discovery of Nipah virus: A personal account. Neurol Asia. 2004;9:59-63. neurology-asia. org/articles/20042_059.pdf

17. Wit E, Munster VJ. Animal models of disease shed light on Nipah virus pathogenesis and transmission. J Pathol. 2015;235(2):196-205. doi: 10.1002/path.4444 JCM.01875-17

18. Karim MM and Rahman MT. Return of Nipah virus: Bangladesh perspective. Bangladesh J Pathol. 2011;26(1):23-25. doi: 10.3329/bjpath.v26i1.9147

19. Epstein JH, Anthony SJ, Islam A, et al. Nipah virus dynamics in bats and implications for spillover to humans. Proc Natl Acad Sci USA. 2020;117(46):2919029201. doi: $10.1073 /$ pnas. 2000429117

20. Outbreaknews. Bangladesh reports two Nipah virus cases in 2021. 2021a. outbreaknewstoday.com

21. Outbreaknews. Nipah virus in Kerala, India: 2021b. outbreaknewstoday.com/nipah-virus-in-kerala-indiawho-details-92774/2021.

22. Babu R. How Kerala brought patients infected with Nipah virus back from death. Hindustan Times. (Newspaper Report). doi: 101608310426209/page 38

23. Sudeep AB, Yadav PD, Gokhale MD, et al. Detection of Nipah virus in Pteropus medius in 2019 outbreak from Ernakulam district, Kerala, India. BMC Infect Dis. 2021;21(1):162. doi: 10.1186/s12879-021-05865-7

24. Rahman MZ, Islam MM, Hossain ME, et al. Genetic diversity of Nipah virus in Bangladesh. Int J Infect Dis. 2021;102:144-151. doi: 10.1016/j.jijid.2020.10.041

25. Broder CC, Weir DL, Reid PA. Hendra virus and Nipah virus animal vaccines. Vaccine. 2016;34(30):35253534. doi: 10.1016/j.vaccine.2016.03.075

26. Lamp B, Dietzel E, Kolesnikova L, et al. Nipah virus entry and egress from polarized epithelial cells. J Virol. 2013;87(6):3143-3154. doi: 10.1128/JVI.02696-12

27. Wong KT, Shieh WJ, Kumar S, et al. Nipah virus infection: pathology and pathogenesis of an emerging paramyxoviral zoonosis. Am J Pathol. 2002;161(6):21532167. doi: $10.1016 /$ S00029440(10)64493-8

28. Devnath P, Masud HMAA. Nipah virus: a potential pandemic agent in the context of the current severe acute respiratory syndrome coronavirus 2 pandemic. New Microbes New Infect. 2021;41:100873. doi: 10.1016/j.nmni.2021.100873

29. Parashar UD, Sunn LM, Ong F, et al. Case control study of risk factors for human infection with a new zoonotic Paramyxovirus, Nipah virus, during a 1998-1999 outbreak of severe encephalitis in Malaysia. J Infect Dis. 2000;181(5):1755-1759. doi: 10.1086/315457

30. Hossain MJ, Gurley ES, Montogomery JM, et al. Clinical presentation of Nipah virus infection in Bangladesh. Clin Infect Dis. 2008;46(7):977-984. doi: 10.1086/529147

31. Tan CT, Goh KJ, Wong KT, et al. Relapsed and late-onset Nipah encephalitis. Ann Neurol. 2002;51(6):703-708. doi: 10.1002/ana.10212

32. Chadha MS, Comer JA, Lowe L, et al. Nipah virus associated encephalitis outbreak, Siliguri, India. Emerg Infect Dis. 2006;12(2):235-240. doi: 10.3201/ eid1202.051247

33. Chong HT, Abdullah S, Tan CT. Nipah virus and bats. 
Neurol Asia. 2009;14:73-76.

34. Mazzola LT, Kelly-Cirino C. Diagnostics for Nipah virus: a zoonotic pathogen endemic to Southeast Asia. BMJ Glob Health. 2019;4:e001118. doi: 10.1136/ bmjgh-2018-001118

35. Hegde ST, Sazzad HMS, Hossain MJ, et al. Investigating rare risk factors for Nipah virus in Bangladesh: 20012012. Ecohealth. 2016;13(4):720-728. doi: 10.1007/ s10393-016-1166-0

36. Ramsundrum V, Tan CT, Chua KB, et al. Kinetics of IgM and IgG seroconversion in Nipah virus infection. Neurol J Southeast Asia. 2000;5:23-28. www.neurology-asia. org/articles/20001_023.pdf

37. Hume F, Peter D, Lee BO, Aziz J, Mike B. Manual of the diagnosis of Nipah Virus infection in animals. 2002:29-31. https://coin.fao.org/coin-static/cms/ media/1/13170263993060/2002_01_high.pdf.

38. Tiong V, Shu MH, Wong WF, AbuBakar S, Chang LY. Nipah Virus infection of immature dendritic cells increases I transendothelial migration across human brain microvascular endothelial cells. Front Microbiol, 2018; 9: 10.3389/fmicb.2018.0274.

39. Danielsa P, Ksiazekb T, Eatona BT. Laboratory diagnosis of Nipah and Hendra virus infections. Microb Infect. 2001;3(4):289-295. doi: 10.1016/S12864579(01)01382-X

40. Torres-Velez FJ, Shieh WJ, Rollin PE, et al. Histopathologic and immunohistochemical characterization of Nipah virus infection in the guinea pig. Vet Pathol. 2008;45(4):576-585. doi: 10.1354/vp.45-4-576

41. Ashraf L. Interventions for prevention of Nipah virus transmission and infection in Bangladesh. Arch Commun Med Publ H/th. 2020;6:66-68.

42. Rahman M, Chakraborty A. Nipah virus outbreaks in Bangladesh: a deadly nonhuman primates with a neutralizing human monoclonal antibody. Science
Trans/ Med. 2014;6(242):242ra82-242ra82.

43. Geisbert TW, Mire CE, Geisbert JB, et al. Therapeutic treatment of Nipah virus infection in nonhuman primates with a neutralizing human monoclonal antibody. Sci Trans Med. 2014;6(242):242ra82. doi: 10.1126/scitranslmed.3008929

44. Chong HT, Kamarulzaman A, Tan CT, et al. Treatment of acute Nipah encephalitis with ribavirin. Annals Neurol. 2001:49(6):810-813. doi: 10.1002/ana.1062

45. Lo MK, Feldmann F, Gary JM, et al. Remdesivir (GS5734) protects African green monkeys from Nipah virus challenge. Sci Transl Med. 2019;11(494):eaau9242. doi:10.1126/scitranslmed.aau9242

46. Dawes BE, Kalveram B, Ikegami T, et al. Favipiravir (T-705) protects against Nipah virus infection in the hamster model. 2018: Sci Rep. 2018;8(1):7604. doi: 10.1038/s41598-018-25780-3

47. Pillai VS, Krishna G, Veettil MV. Nipah Virus: Past outbreaks and future containment. Viruses. 2020;12(4):465. doi: 10.3390/v12040465

48. Geisbert TW, Bobb K, Borisevich V, et al. A single dose investigational subunit vaccine for human use against Nipah virus and Hendra virus. npj Vaccines. 2021;6(1):23.doi: 10.1038/s41541-021-00284-w

49. McLean RK, Graham SP. Vaccine Development for Nipah Virus Infection in Pigs. Front Vet Sci. 2019;6:16. doi:10.3389/fvets.2019.00016

50. Johnson K, Bu M, Freiberg AN. Recent advances in combating Nipah virus. Fac Rev. 2021;10:74. doi: 10.12703/r/10-74

51. Walpita $\mathrm{P}$, Cong $\mathrm{Y}$, Jahrling $\mathrm{PB}$, et al. A VLP-based vaccine provides complete protection against Nipah virus challenge following multiple-dose or single dose vaccination schedules in a hamster model. NPJ Vaccines. 2017;2:21. doi: 10.1038/s41541-017-0023-7 